\section{M1 and M2 macrophages phenotypes modulation after stimuli with materials used in endodontic treatment}

\author{
Raquel Assed Bezerra Da Silva (D1; Léa Assed Bezerra Da Silva (D1, \\ Edson Alves Gabriel-Junior (102, Carlos Arterio Sorgi (D)3, Lúcia Helena \\ Faccioli (1)2, Vivian Vicentin Massoni (101; Paulo Nelson-Filho (D); \\ Carolina Maschietto Pucinelli (D).
}

The aim of this study was to evaluate the M1 and M2 macrophage modulation after stimuli with different materials used during endodontic treatment. In bone marrow-derived macrophage cell culture, from males C57BL/6 wild-type (WT) mice, gene expression analysis of markers to M1 and M2 macrophages was performed by qRT-PCR (Cxcl10, CxCL9, iNOS, Arg1, Chil3, Retnla and MRC1) and cytokine quantification by Luminex ${ }^{\circledR}$ (GM-CSF, IL-10, IL-6, IL-1 $\beta$ and TNF- $\alpha$ ) after exposure to the five endodontic sealers: AH Plus, Sealapex Xpress, Endosequence BC Sealer, BioRoot RCS and a calcium hydroxide-based paste. For normal values, ANOVA test was used, followed by Tukey post-test. For non-normal values, the Kruskall-Wallis test was used. BioRoot ${ }^{\mathrm{TM}} \mathrm{RCS}$ and EndoSequence BC Sealer ${ }^{\mathrm{TM}}$ stimulated the highest expression of markers for M1 macrophages, while calcium hydroxidebased paste stimulated the lowest expression of these gene markers. For M2 protein markers, BioRoot ${ }^{\mathrm{TM}}$ RCS presented the highest stimulation while calcium hydroxide-based paste also presented the lowest stimulation. It was concluded that all the evaluated filling materials increased the genetic expression of pro- and anti-inflammatory markers: TNF- $\alpha$ and IL-10 respectively. The others proinflammatory mediators showed differences against the filling materials. However, this process did not induce the inflammatory response polarization, resulting in a hybrid macrophage.
1Departamento de Clinica InfantilUniversidade de São Paulo, Faculdade de Odontologia de Ribeirão Preto, Ribeirão Preto, São Paulo, Brasil.

2Departamento de Análises Clínicas, Toxicológicas e Bromatológicas - Universidade de São Paulo, Faculdade de Ciências

Farmacêuticas de Ribeirão Preto, Ribeirão Preto, São Paulo, Brasil.

3Departamento de Quimica - Universidade de São Paulo, Faculdade de Filosofia Ciência e Letras de Ribeirão Preto, Ribeirão Preto, São Paulo' Brasil.

Correspondence: Carolina Maschietto Pucinelli University of São Paulo, School of Dentistry of Ribeirão Preto, Av. do Café s/n - Monte Alegre - Ribeirão Preto - SP - Brazil, CEP: 14040-904 e-mail- carolinamaschietto@yahoo.com.br

Key Words: macrophages, cytokines, periapical periodontitis, root canal obturation, calcium hydroxide.

\title{
Introduction
}

Apical periodontitis formation requires that pattern recognition receptors (PRRs) expressed by cells from the immune system, recognize the pathogen - from caries- or the damage - from dental trauma through pathogen-associated molecular pattern (PAMPs) or damage-associated molecular pattern (DAMPs) (1). This process will trigger the release of cytokines and chemokines by inflammatory cells, such as macrophages, initiating the inflammatory response (1). Depending on the aggressor stimulus, the amount of cytokines produced and the duration of exposure, macrophages can be polarized into two main phenotypes by the microenvironment stimulation: "classically activated" macrophages or M1 and "alternatively activated" macrophages or M2 (2).

M1 macrophages are mainly related to the onset of the immune response and the proinflammatory cytokines production, while the M2 phenotype modulates the inflammatory response and wound repair (2). M1 macrophages activation occurs through Interferon gamma (IFN- $\gamma$ ), Bacterial Lipopolysaccharides (LPS) and Macrophage and Granulocyte Colony Stimulating Factor (GM-CSF) stimuli (3). On the other hand, stimuli such as MCSF-1, IL-4, IL-10, TGF- $\beta$ and IL-13, fungi and helminth infections can lead macrophage $\mathrm{M} 2$ phenotype polarization $(3,4)$.

In dentistry, a recent study demonstrated that manipulation of endogenous M2 macrophages with CCL2, an important chemotactic factor for these cells, prevented alveolar bone loss in mouse periodontitis models (5). Specific in the Endodontics field, studies have evaluated some aspects involved with the ability of different materials to stimulate macrophages polarization $(6,7,8,9)$.

The interaction of the filling material, as well as the intracanal medication, with the periapical tissues through the apical foramen can modulate the inflammatory response (10). Thus, it is of crucial importance to carry out research to evaluate the effect of different materials used during endodontic 
treatment on the modulation of the inflammatory process and the immune system. Studies have been carried out in order to investigate the ability of endodontic filling materials to modulate the inflammatory response (11), and observed the ability of some endodontic sealers in stimulating the expression of inflammatory cytokines. In the same way, Jeanneau, et al. (10) evaluated the ability of zinc oxide and eugenol-based materials in modulating the expression of pro-inflammatory cytokines. They concluded that Endomethasone N (Septodont) was able to inhibit the expression of these cytokines, generating an anti-inflammatory effect, which could reduce the inflammatory reaction, improving periapical repair and, consequently, improving the clinical outcome. Both studies demonstrated the importance and the ability of endodontic sealers to modulate the inflammatory response $(10,11)$.

Considering the ability of endodontic filling materials in modulating the inflammatory response and knowing the macrophage polarization importance in the immune response, studies are needed in order to understand macrophage polarization modulated by different filling materials and intracanal medications for safer use during the clinical practice. The aim of the study was to evaluate the ability of different materials used during endodontic treatment (filling material and intracanal dressing) in modulating the macrophage phenotype into $\mathrm{M} 1$ and $\mathrm{M} 2$. The null hypothesis tested was that these filling materials and intracanal medication are not able to modulate the macrophage phenotype in M1 and M2 macrophages.

\section{Material e methods}

\section{Bone Marrow Cell Culture Study}

This work was first approved by the Animal Use Ethics Committee of the Ribeirão Preto School of Dentistry of the University of São Paulo (2016.1.645.58.0). Three males C57BL/6 wild-type (WT) mice, aged 6 to 8 weeks, weighing 20 grams were used. The animals were kept with standard feed and free access to water. After 1 week of setting, they were anesthetized by intramuscular injection with Ketamine ( $150 \mathrm{mg} / \mathrm{kg}$ body weight) and Xylazine $(7.5 \mathrm{mg} / \mathrm{kg}$ body weight) and then sacrificed in a carbon dioxide (CO2) chamber.

After femurs and tibias obtaining, bone marrow cells were extracted by washing the inside of the bones with minimal essential medium (DMEM - Dulbecco) supplemented with $10 \mathrm{mM}$ L-glutamine, $100 \mathrm{U} / \mathrm{mL}$ penicillin, $100 \mathrm{U} / \mathrm{mL}$ streptomycin, and $20 \%$ horse serum. Suspension cell number was determined using Neubauer chamber and Turk's solution. Cell viability was determined by excluding cells stained blue in the Trypan Blue solution and were used when viability was greater than $90 \%$.

The isolated cells $\left(10^{6} / \mathrm{mL}\right.$ ) were cultured for 7 days (with DMEM supplemented with $10 \mathrm{mM} \mathrm{L}$ glutamine, $100 \mathrm{U} / \mathrm{mL}$ penicillin and $100 \mathrm{U} / \mathrm{mL}$ streptomycin, with $20 \%$ horse serum and $30 \%$ L929conditioned medium and the suspension was named as bone marrow derived macrophages (BMDM).

BMDMs were seeded in 48-well microculture plates with a density of $5 \times 10^{5}$ cells/well and incubated at $37^{\circ} \mathrm{C}$ in a humidified 5\% CO2 atmosphere for 18 hours. After this, BMDM cultures were exposed to different dilutions proportions in DMEM medium $(1: 10,1: 100,1: 300$ and 1:1000) of the following materials: AH Plus ${ }^{\mathrm{TM}}$ (Dentsply, Johnson City, EUA), BioRoot ${ }^{\mathrm{TM}}$ RCS (Septodont, Lancaster, EUA), EndoSequence BC Sealer ${ }^{\mathrm{TM}}$ (Brasseler, Savannah, EUA), Sealapex Xpress ${ }^{\mathrm{TM}}$ (Kavo Kerr, Orange, EUA) and Calen ${ }^{\circledR}$ (S.S White Artigos Dentários, Rio de Janeiro, RJ, Brazil). The materials used in this study are presented in Table 1, as well their manufacturers and the composition. DMEM medium without the addition of materials was used as negative control. The BMDMs with the different stimuli were incubated at $37^{\circ} \mathrm{C}$ in a humidified 5\% CO2 atmosphere for 24 hours. 
Table 1. Description of materials used and their respective manufacturers, batch number and composition.

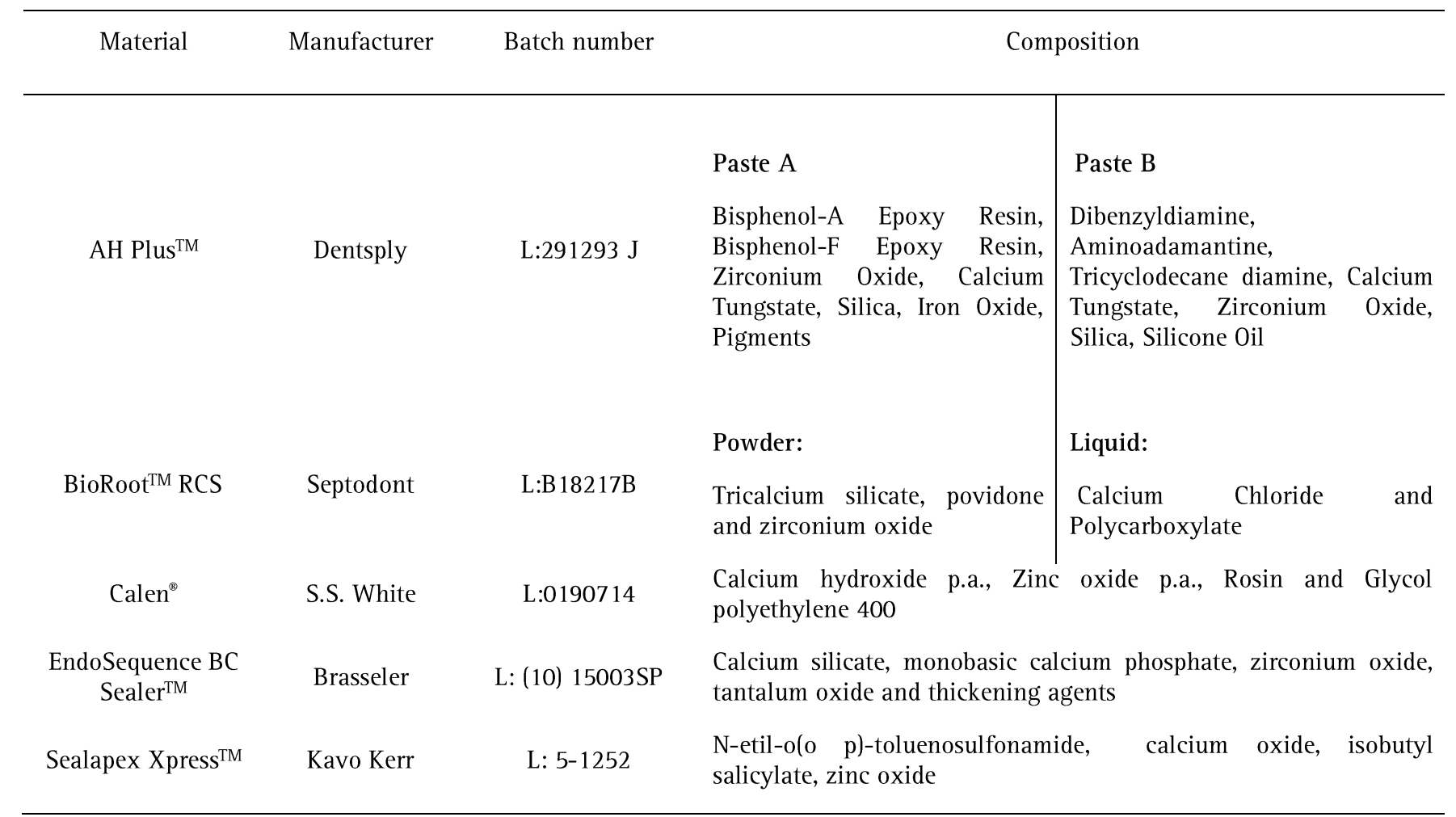

Culture supernatants were collected and stored at $-20^{\circ} \mathrm{C}$ until their use for Luminex ${ }^{\circledR}$ assay and the mRNA obtained from the cells was submitted to qRT-PCR analysis for M1 and M2 macrophages analysis.

\section{MT Assay}

To assess cell viability after BMDM stimulation with different materials, the MT assay was employed using the 3- (4,5-dimethylthiazol-2-yl) -2,5-diphenyltetrazolium water soluble tetrazolium salt (Sigma). The absorbance was determined at a wavelength of $595 \mathrm{~nm}$ in a spectrophotometer (Molecular Devices, USA). DMSO ( $5 \% \mathrm{v} / \mathrm{v})$ was used as positive control for cytotoxicity. Absorbance was used as a cell viability index and the results were expressed as percentages relative to the negative control group (culture medium) compared to the stimuli.

\section{qRT-PCR}

The qRT-PCR was performed according to previously published studies (12). RNA extraction was made using the PureLink RNA Mini Kit manufacturer's protocol (Ambion, Life Technologies, Carlsbad, CA, USA). The amount of extracted RNA was estimated with NanoDrop One (Thermo Fisher Scientific Inc., Wilmington, DE). The reverse transcription reaction was based on the protocol proposed by the Taqman ${ }^{\circledR}$ manufacturer.

The amplification reaction of each gene consisted of cDNA specific primers, specific fluorescent probes and MasterMix reagent (Applied Byosistems). Glyceraldehyde-3-phosphate dehydrogenase (Gapdh) and $\beta$-actin (Actb) were analyzed as housekeeping genes. The expression of Cxc110, CxCL9 and iNOS mRNA (markers of M1 phenotype) and Arg1, Chil3, Retnla and Mrc1 (markers of M2 phenotype) were evaluated. Also, as control, were evaluated IL-4 and IFN- $\gamma$. Reactions were performed in duplicate for each sample. After sample amplification, relative quantification was performed using the 2- $\Delta \Delta \mathrm{Ct}$ method. The data were expressed in Fold regulation in relation to Control Group (DMEM medium).

\section{Total Protein Quantification}

In order to normalize the value found in the Luminex ${ }^{\circledR}$ assay (Luminex ${ }^{\circledR}$ value/total amount of protein for each sample), the total protein quantification was performed each sample using the BCA Protein Assay Kit (Novagen - Darmstadt, Germany). The protocol followed was according to the manufacturer's instructions and measured using a spectrophotometer at $562 \mathrm{~nm}$ wavelength. 


\section{Cytokine Quantification Using Luminex ${ }^{\circledR}$}

GM-CSF, IL-6, IL-1 $\beta$ and TNF- $\alpha$ (phenotype markers M1) and IL-10 (M2 phenotype markers) concentrations were analyzed in duplicate in the cell culture supernatant by Luminex ${ }^{\circledR}$ assay using the Millipore 7-plex kit (Millipore Corporation, Billerica, MA, USA). Assays were performed in 96-well plates following the manufacturer's instructions. Sample concentrations were quantified from the standard curve using a third order polynomial equation and GraphPadPrism 5 software (GraphPad Software Inc., La Jolla, CA, USA), expressed as $\mathrm{pg} / \mathrm{mL}$. For each sample, the normalization value was obtained dividing the Luminex ${ }^{\circledR}$ results by the total proteins amount.

\section{Statistical analysis}

For quantitative variables, the values were expressed as mean and standard deviation. To evaluate the normality of the samples were used D'Agostino-Pearson and Shapiro-Wilk tests. To compare the groups after qRT-PCR, two-way ANOVA was used, followed by Tukey post-test. To compare the other analysis, the ANOVA test was used, followed by the Tukey post-test if the distribution was normal. Otherwise, the Kruskall-Wallis test was used. The adopted significance level was 5\%. All analyzes and graphical representations were performed with the aid of GraphPad Prism 7 Software (GraphPad Software).

\section{Results}

\section{MTT Assay}

The MTT assay results (Figure 1) showed that up 1:100 dilution proportion the results regarding satisfactory cell viability in all experimental groups analyzed (AH Plus ${ }^{\mathrm{TM}}$, BioRoot ${ }^{\mathrm{TM}}$ RCS, Calen ${ }^{\circledR}$, EndoSequence BC Sealer ${ }^{\top M}$ and Sealapex Xpress $^{\top M}$ ), with values greater than $90 \%$. Therefore, all subsequent gene expression and protein assay tests were performed at this concentration for all materials.

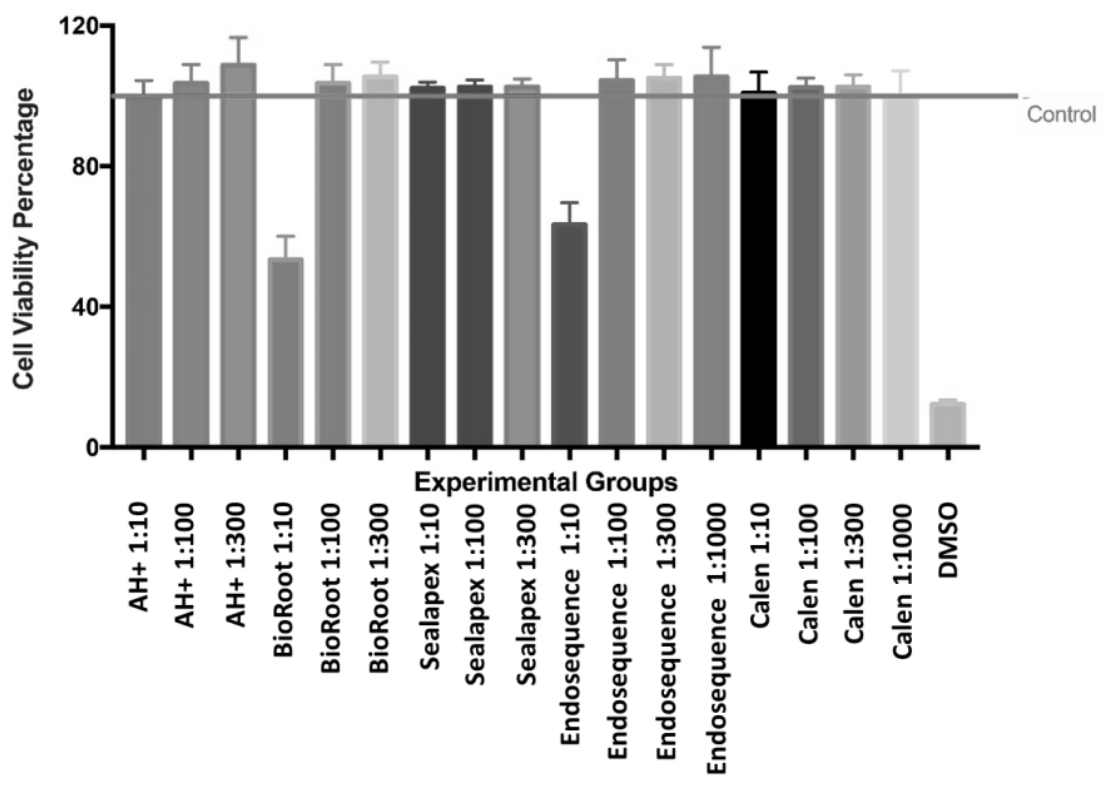

Figure 1. Representative graphic of MTT assay after MDBM cells stimulation with AH Plus ${ }^{\mathrm{TM}}$, BioRoot ${ }^{\mathrm{TM}}$ RCS, Calen ${ }^{\oplus}$, EndoSequence BC Sealer ${ }^{\mathrm{TM}}$ and Sealapex Xpress ${ }^{\mathrm{TM}}$ at different concentrations.

\section{qRT-PCR}

Markers of M1 phenotype: Cxcl10, CxCL9 and iNOS

The control INF-y showed high expression in all analysis for M1 phenotype, with statistical significant difference from the control (medium). On the other hand, IL-4 didn't show difference ( $p>0.05)$ from control after analysis of M1 phenotype markers (Figure 2). 


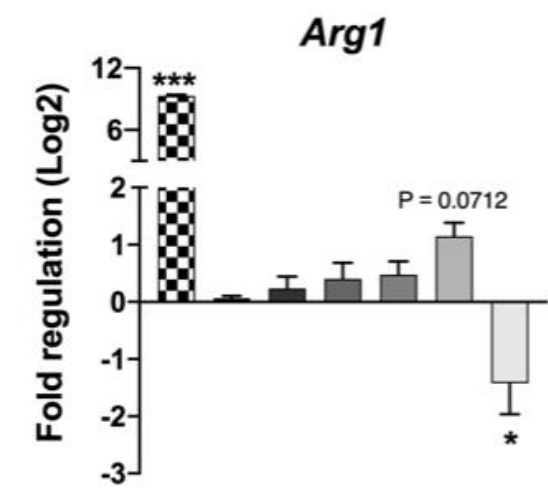

Retnla

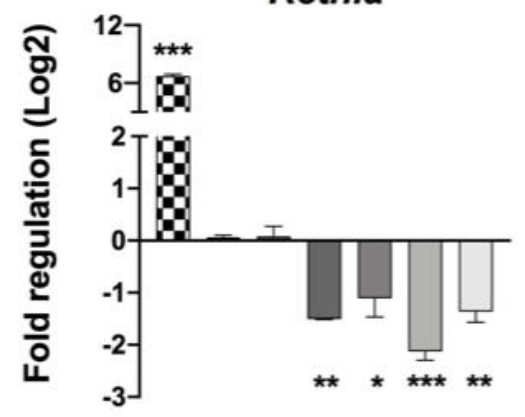

Chil3

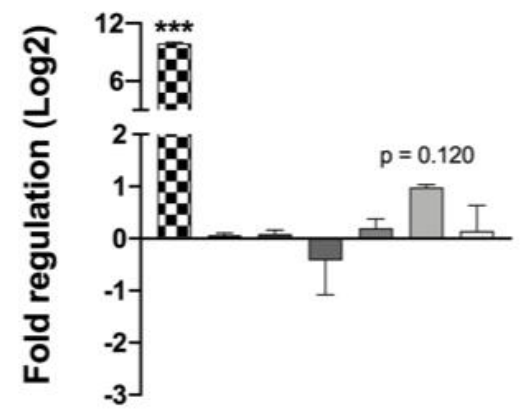

Mrc1

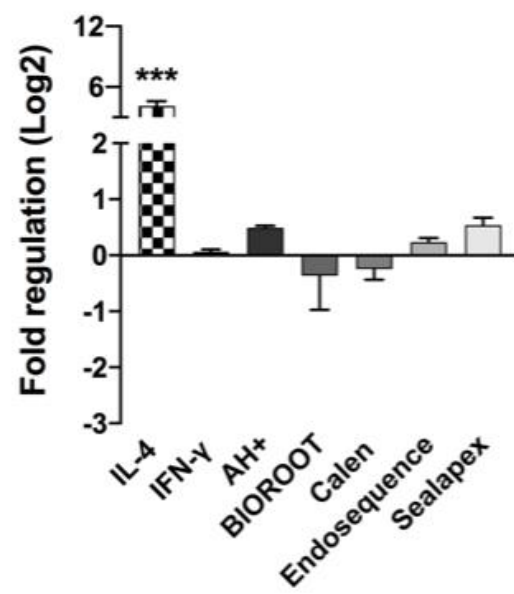

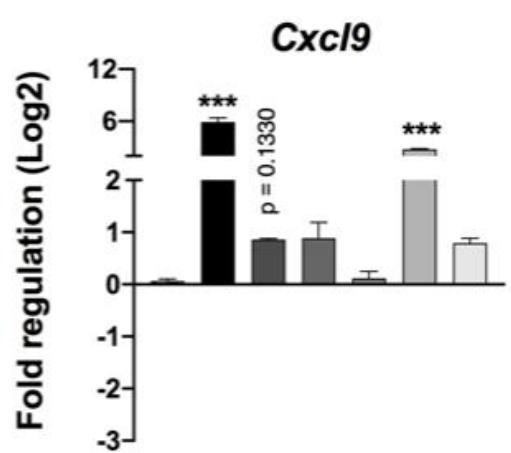

Cxcl10

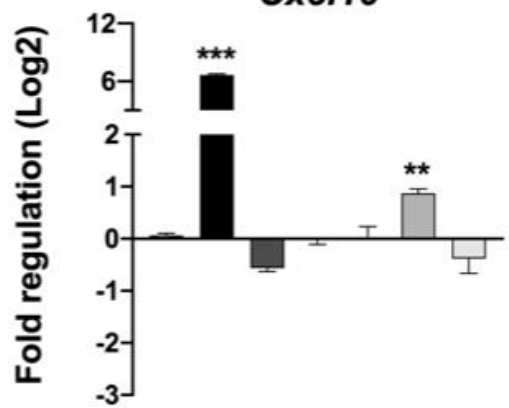

iNos

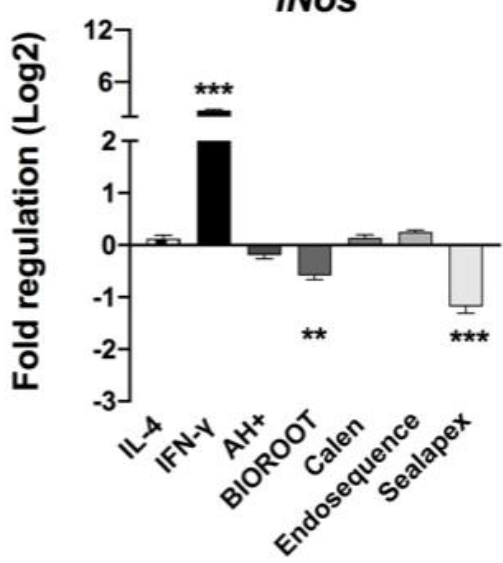

Figure 2. Representatives graphics of qRT-PCR performed with markers of M1 phenotype: Cxcl10, CxCL9 and iNOS and markers of M2 phenotype: Arg1, Retnla, Chil3 and MRC1 besides of the controls IL-4 and IFN- $\gamma$ after stimuli with AH Plus ${ }^{\mathrm{TM}}$, BioRoot ${ }^{\mathrm{TM}}$ RCS, Calen ${ }^{\circledR}$, EndoSequence BC Sealer ${ }^{\mathrm{TM}}$, and Sealapex Xpress ${ }^{\mathrm{TM}}$. ${ }^{*} p<0.05,{ }^{* *} p<0.001{ }^{* * *}, p<0.0001$. INF- $\gamma$ and IL-4 showed high expression in all analysis for $M 1$ phenotype $(p>0.0001)$ and $M 2$ phenotype $(p>0.0001)$ respectively. In the analysis of $M 1$ markers, EndoSequence BC Sealer ${ }^{\mathrm{TM}}$ presented a statistically significant difference from control (medium) in Cxcl10 ( $\left.p>0.01\right)$ and CxCL9 $(p>0.001)$ expression. BioRoot ${ }^{\mathrm{TM}} \mathrm{RCS}(\mathrm{p}<0.001)$ and Sealapex Xpress $\mathrm{T}^{\mathrm{TM}}(\mathrm{p}<0.01)$ presented a down regulation for iNOS expression. In the analysis of M2 markers, Sealapex Xpress ${ }^{\mathrm{TM}}$ was downregulated $(p<0.05)$ for Arg 1 analysis. BioRoot ${ }^{\mathrm{TM}} \mathrm{RCS}(\mathrm{p}<0.01)$, Calen ${ }^{\circledR}$ $(p<0.01)$, EndoSequence BC Sealer ${ }^{\mathrm{TM}}(p<0.001)$ and Sealapex Xpress ${ }^{\mathrm{TM}}(\mathrm{p}<0.01)$ downregulated the Retnla expression. For Chil3 and Mrc1 expression, none of tested materials showed expression with statistical significant difference from the control. 
Cxcl10 analysis revealed that EndoSequence BC Sealer ${ }^{T M}(p>0.01)$ was significantly more expressed when compared to the control (medium). Similar results were observed after analysing CxCL9. EndoSequence BC Sealer ${ }^{\mathrm{T} M}$ presented a statistically significant difference from control $(p<0.001)$. BioRoot $^{\mathrm{TM}}$ RCS $(p<0.001)$ and Sealapex Xpress $^{\mathrm{TM}}(\mathrm{p}<0.01)$ presented a down regulation for iNOS expression(Figure 2).

\section{Markers of M2 phenotype: Arg1, Retnla, Chil3 e MRC1}

The control IL-4 showed high expression in all analysis for M2 phenotype, with statistical significant difference from the control (medium). On the other hand, INF- $\gamma$ didn't show difference ( $p>0.05$ ) from control after analysis of M2 phenotype markers. Arg1 analysis revealed that Sealapex Xpress ${ }^{\mathrm{TM}}$ was downregulated $(p<0.05)$. BioRoot ${ }^{T M}$ RCS $(p<0.01)$, Calen ${ }^{\circledR}(p<0.01)$, EndoSequence BC Sealer ${ }^{T M}(p<0.001)$ and Sealapex Xpress ${ }^{\mathrm{TM}}(\mathrm{p}<0.01)$ downregulated the Retnla expression. After analysis for Chil3 and Mrc1 expression, none of tested materials showed expression with statistical significant difference from the control (Figure 2).

\section{Luminex ${ }^{\circledR}$ Assay}

Macrophage M1 polarization marker: GM-CSF, IL-6, IL-1 $\beta$ and TNF- $\alpha$

The data analysis showed that the amount of GM-CSF found after stimulation with AH Plus, BioRoot and EndoSequence was statistically different when compared to the group of non-stimulated BMDM cells ( $p=0.024)$, with the lowest values. In addition, a statistical difference was observed between BioRoot and Sealapex materials, with the highest values observed after stimulation with BioRoot $(p<0.05)$ (Figure $3 A)$.

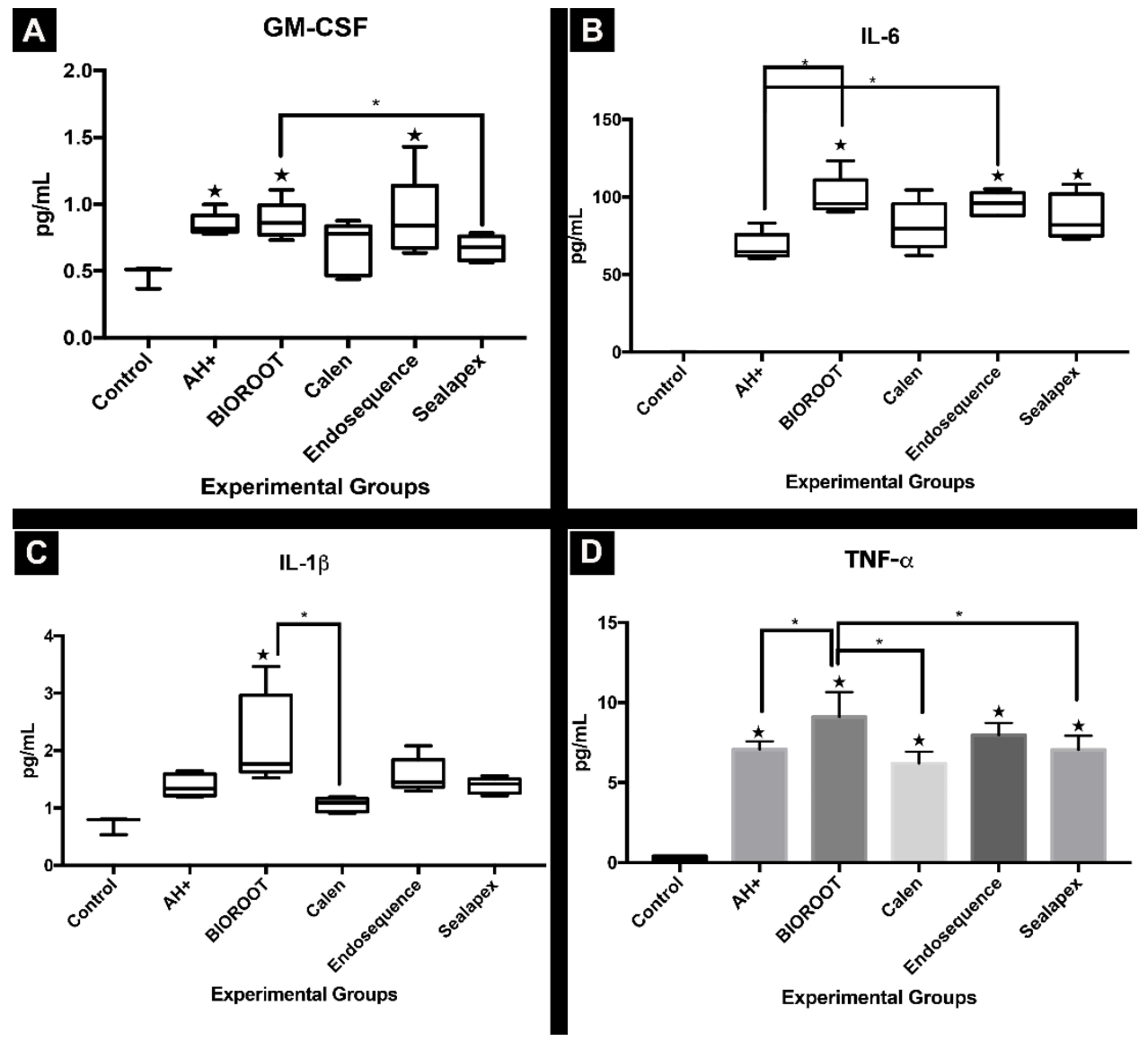

Figure 3. Representatives graphics of amount of GM-CSF (A), IL-6 (B), IL-1 $\beta$ (C) and TNF- $\alpha$ (D) after stimuli with AH PlusTM, BioRootTM RCS, Calen ${ }^{\circledR}$, EndoSequence BC SealerTM, and Sealapex XpressTM. $\left(^{*}\right)$ means statistical difference among groups. $\left({ }^{\star}\right)$ means statistical difference between the experimental groups compared with the control group. Note that for GM-CSF, IL-6 and IL-1 $\beta$ the data distribution was not normal and therefore the Kruskal-Wallis statistical test was used. For TNF- $\alpha$ the data distribution was normal and therefore the ANOVA statistical test was used. 
The lowest IL-6 values were observed in the AH Plus, Calen and control groups. There was a difference when the control group was compared with BioRoot, EndoSequence and Sealapex. AH Plus also showed a statistically significant difference with BioRoot and EndoSequence $(p=0.003)$ (Figure 3B).

Higher IL-1 $\beta$ level was observed after BMDM stimulation with BioRoot. The lowest values, however, were observed when culture medium was used and when Calen paste, AH Plus, Endosequence and Sealapex were the stimulating factors. In this sense, a statistical difference was observed between BioRoot when compared to the control group (culture medium) and Calen ( $p=0.0008)$ (Figure $3 \mathrm{C}$ ).

All experimental groups were statistically different $(p<0.05)$ from the culture medium group (control) with $p$-value $<0.0001$, and the medium presenting the lowest amounts of TNF- $\alpha$. The BioRoot group, in turn, had significantly higher values when compared to the Calen, Sealapex and AH Plus groups $(p<0.05)$ (Figure 3D).

After data analysis regarding the M1 polarization quantification, it was observed that the BioRoot ${ }^{\mathrm{TM}}$ RCS and EndoSequence BC Sealer ${ }^{\mathrm{TM}}$ materials presented the highest amount of inflammatory mediators typically from M1 function, suggesting that they can activate this macrophage response more strongly. The opposite was observed by analyzing the Calen group, where smaller amounts of these markers were observed after stimulation of BMDM cell culture, suggesting a lower ability of this material to stimulate those macrophages to a $\mathrm{M} 1$ response.

\section{Macrophage M2 polarization marker: IL- 10 (Figure 4)}

All experimental groups presented higher amounts of IL-10 compared to culture medium $(p<0.05)$. In addition, the BioRoot-stimulated group also had larger amounts than the Calen group $(p<0.05)$.

The data analysis related to the quantification of M2 polarization marker proteins revealed that BioRoot ${ }^{\mathrm{TM}} \mathrm{RCS}$ showed a higher number of the M2 macrophages marker, suggesting its ability to induce macrophages for this subtype. The stimulation with Calen paste, in turn, presented the smallest amount of M2 macrophages marker, suggesting a lower capacity of this material to polarize macrophages for this subtype.

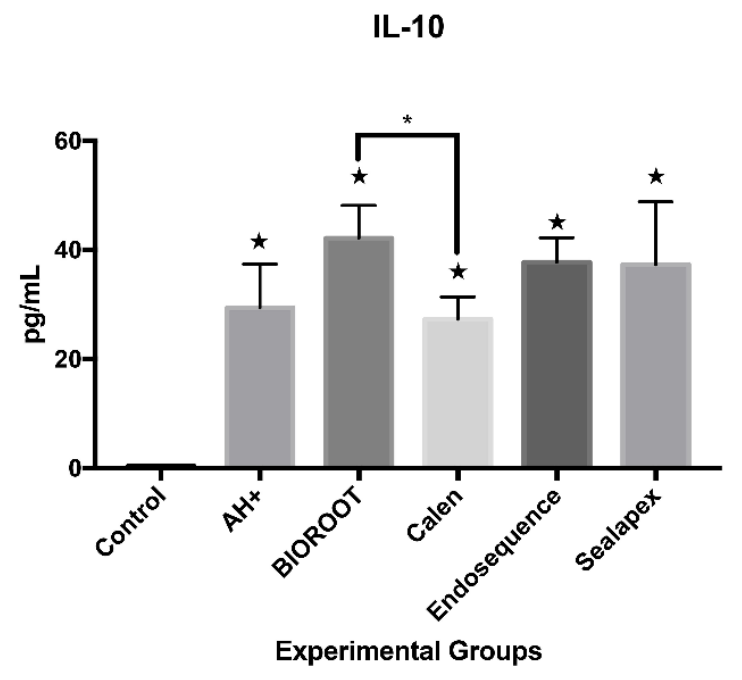

Figure 4. Representative graphic of IL-10 expression after stimuli with AH Plus ${ }^{\mathrm{TM}}$, BioRootTM RCS, Calen ${ }^{\circledR}$, EndoSequence BC Sealer ${ }^{\mathrm{TM}}$, and Sealapex Xpress ${ }^{\mathrm{TM}}$. $\left({ }^{*}\right)$ means statistical difference among groups. $(\star)$ means statistical difference between the experimental groups compared with the control group. Note that for IL-10 the data distribution was normal and therefore the ANOVA statistical test was used. 


\section{Discussion}

In order to clarify whether new and well-known endodontic treatment materials also have properties that favor periapical repair, the present study evaluated four filling materials (AH Plus ${ }^{\top M}$ epoxy resin-based material; BioRoot ${ }^{\mathrm{TM}} \mathrm{RCS}$ - tricalcium silicate-based material; EndoSequence BC Sealer ${ }^{\mathrm{TM}}$ - calcium silicate bioceramic material; and Sealapex $\mathrm{Xpress}^{\mathrm{TM}}$ - calcium hydroxide material), in addition to Calen ${ }^{\circledR}$ paste - calcium hydroxide material, to identify its ability to modulate the macrophages in $\mathrm{M} 1$ and $\mathrm{M} 2$ phenotypes. The results suggested that BioRoot ${ }^{\mathrm{TM}} \mathrm{RCS}$ and EndoSequence $\mathrm{BC}$ Sealer ${ }^{\mathrm{TM}}$ stimulated the highest expression of gene markers for M1 macrophages, while Calen ${ }^{\circledR}$ paste stimulated the lowest expression of these markers. For M2 markers, BioRoot ${ }^{\mathrm{TM}} \mathrm{RCS}$ presented the highest stimulation while Calen ${ }^{\circledR}$ paste also presented the lowest stimulation.

IL-1 $\beta$ and TNF- $\alpha$ are important proinflammatory mediators for the initial immune reaction (12) and can be secreted by macrophages (13). In addition, IL-1 $\beta$ stimulates bone resorption by increasing osteoclast formation (14). TNF- $\alpha$ is known to be a classic proinflammatory mediator (15). M1 macrophages show high capacity to secrete cytokines such as IL-1 $\beta$ and TNF- $\alpha$, but also IL-12 and IL-18 (3).

In this sense, Zhu et al. (8) found, in macrophage cell culture, that both iRoot SP (Innovative BioCeramix Inc., Vancouver, Canada) a bioceramic material, and MTA (Dentsply, Tulsa, OK) silicate and calcium-based material, induced the expression of IL-1 $\beta$ and TNF- $\alpha$. Our results showed a similar event. The results of the present study showed that MTA-based material (BioRoot ${ }^{\mathrm{TM}} \mathrm{RCS}$ ) also induced high IL$1 \beta$ production, being statistically different from control (culture medium) and also different from Calen ${ }^{\circledR}$ paste. Regarding TNF- $\alpha$, our results agree with Zhu et al. (8) presenting BioRoot ${ }^{\mathrm{TM}}{ }^{\mathrm{RCS}}$ and EndoSequence BC Sealer ${ }^{T M}$ high production of this cytokine. The other materials evaluated (AH Plus ${ }^{\mathrm{TM}}$, Calen $^{\circledR}$ and Sealapex Xpress $^{\mathrm{TM}}$ ) also presented statistical differences when compared to the control. In addition, BioRoot ${ }^{\mathrm{TM}}$ RCS is statistically potent production when compared with $\mathrm{AH}$ Plus ${ }^{\mathrm{TM}}$, Calen ${ }^{\circledR}$ and Sealapex Xpress $^{\top \mathrm{M}}$. Zhu et al. (8) also evaluated the gene expression of IL-12 (expressed in high concentration during the initial inflammatory reaction by M1 macrophages) and IL-10 (expressed by M2 macrophage and related to the repair process). They concluded that both $M 1$ and M2 phenotypes could be induced by iRoot SP and MTA. The present study, using other markers and other methodologies, observed that not only MTA-based or bioceramic materials, but all five materials tested, induced the expression of cytokines markers of both $\mathrm{M} 1$ phenotype and phenotype $\mathrm{M} 2$, display a non-polarized macrophage phenotype, but a functional cluster of inflammatory activity.

Yuan et al. (16) evaluated MTA and iRoot SP materials in cell culture under conditions that mimicked inflammation. IL-1 $\beta$, TNF- $\alpha$ and IL- 6 were significantly increased when cells were stimulated by those materials. In agreement, the present study demonstrated that when IL- 6 was evaluated, it presented the highest amount after stimulation with BioRoot ${ }^{\mathrm{TM}} \mathrm{RCS}$ and EndoSequence BC Sealer ${ }^{\mathrm{TM}}$, and also the Sealapex Xpress ${ }^{\mathrm{TM}}$ group showed significantly higher values when compared to the control. IL-6 is a classically cytokine related to M1 macrophage polarization (17). This cytokine promotes lymphocyte activation, proliferation and survival during the immune response (18). Gomes-Filho, et al. (19), evaluated three different endodontic cements (Endo-CPM - MTA-based cement, Sealapex and MTA). They concluded that all materials induced IL-6 release, but the amount was not statistically different from the control group (culture medium). Our results disagree with these authors since the Sealapex Xpress ${ }^{\top M}$, BioRoot ${ }^{\mathrm{TM}}$ RCS, and EndoSequence BC Sealer ${ }^{\mathrm{TM}}$ groups induced IL-6 expression and were different from the control group. Those differences could be explained by specific methodology steps like cell lineage used for the evaluation. However, we agree that the materials evaluated may play an important role in modulating inflammation.

In another study, Martinho, et al. (20) observed, in cell culture, increased expression of IL-6, IL-8 and TNF- $\alpha$ after stimulation with AH Plus. We agree with regard to TNF- $\alpha$ expression, since our results also demonstrated that $\mathrm{AH} \mathrm{Plus}^{\mathrm{TM}}$ stimulated greater expression of this cytokine compared to the control group. However, our results demonstrated that AH Plus ${ }^{T M}$ stimulated the lowest amounts of IL-6, showing no statistically significant difference from the control group. Again, one of the factors that can cause this difference is the fact that those authors used immortalized human pulp cell culture, not BMDM as the present study. Still related to IL-6, in monocyte cell culture from human blood, Souza, et al. (11) observed that AH Plus ${ }^{\mathrm{TM}}$ values did not differ from the control group, agreeing with our results. However, when Endosequence was evaluated by them, there was no difference compared to the control group. We 
disagree with this result, since our results revealed that the EndoSequence $\mathrm{BC}$ Sealer ${ }^{\mathrm{TM}}$ showed difference when compared with both control group and $\mathrm{AH}$ Plus ${ }^{\mathrm{TM}}$.

Bacterial LPS and cytokines such as IFN- $\gamma$, TNF- $\alpha$ and Granulocyte-macrophage colony-stimulating factor (GM-CSF) induce the macrophage polarization to M1 phenotype. When GM-CSF was quantified in present study, the highest values were observed after stimulation with EndoSequence BC Sealer ${ }^{\mathrm{TM}}$, followed by BioRoot ${ }^{\mathrm{TM}} \mathrm{RCS}$ and $\mathrm{AH}$ Plus ${ }^{\mathrm{TM}}$. All the materials presented statistical differences with the control group. In general, the evaluated materials were able to promote the proinflammatory cytokines expression and the onset of the inflammatory response, having an effect on the repair process of the periapical lesion. After all, it is known that inflammation is the result of the protection against an infection spread, followed by resolution, in other words, the restoration of affected tissues into their normal structural and functional states (21).

In addition, according to the parameters adopted for the characterization of macrophages, it was observed that all materials studied were able to modulate macrophages for the M1 phenotype. M1 macrophages are activated by intracellular pathogens, LPS, IFN- $\gamma$, TNF- $\alpha$ and GM-CSF. In addition, they are able to mediate resistance against pathogens, present antimicrobial and anti-tumor activities, high nitrogen and reactive oxygen production, and promote Th1 responses (22).

However, our results also demonstrated that all materials studied were generally able to promote the production of IL-10. IL-10 is an important immunoregulatory cytokine expressed by several inflammatory cells, including macrophages (19). The inflammatory resolution requires an adequate and coordinated balance of pro and anti-inflammatory mechanisms. Proinflammatory mechanisms are responsible to eliminate the pathogen and are then negatively modulated by IL-10, allowing the repair process (23). The present study demonstrated that all endodontic materials tested presented significantly higher amounts when compared to the IL-10 levels in the control group. This demonstrates that these materials have the ability to stimulate macrophages to produce IL-10 and could play a role during tissue repair by stimulating anti-inflammatory mechanisms. Our results agree with Souza, et al. (11). They evaluated the amount of IL-10 in cell culture after stimulation with the AH Plus ${ }^{\mathrm{TM}}$ and EndoSequence $\mathrm{BC}$ Sealer ${ }^{\mathrm{TM}}$ cements, and found that the amounts of this cytokine were higher when compared these materials to the control group.

According to the parameters used in the present study for M2 macrophages characterization, it was observed that all materials studied were able to polarize macrophages for this phenotype. Yeh, et al. (9) pointed out that MTA participated in the repair process, as it has demonstrated the ability to differentiate macrophages into M2. However, Yeh, et al. (9) selected just CD206, a classic marker to alternatively activated macrophages - M2 when they performed flow cytometry. Our results demonstrated that the MTA-based material BioRoot ${ }^{\mathrm{TM}} \mathrm{RCS}$ was able to polarize macrophages for both $\mathrm{M} 2$ and $\mathrm{M} 1$ phenotypes. In another study, after tube implantation containing MTA on mice subcutaneous tissue, M2 macrophages accumulated in the implanted area, suggesting that the repair process involves this cell type (6). The same was observed after performing MTA pulpotomy in rat molars, it has been suggested that M2 macrophages participate in the early repair process (7).

In addition, qRT-PCR assay did not show a regulation pattern of macrophage polarization. Although some statistical differences after the PCR analyses, with specific differences, were found, the tested materials were not able to polarize the macrophages to a specific phenotype.To identify polarization, they expressions should follow the pattern of the IL-4 and IFN- $\gamma$ controls, with increased expression in M2 pattern and decreased in the M2 pattern.

Finally, our results demonstrated that the evaluated materials were able to induce a mixed macrophage pattern. Similarly, studies using biomaterials such as biofunctionalized scaffolds (24) demonstrated that macrophages exhibited hybrid phenotypes, that is, exhibiting characteristics of the M1 and M2 simultaneously. In their review, Witherel, et al. (25) concluded that the role and function of macrophages exhibiting a hybrid phenotype remain uncertain in biomaterial-mediated fibrosis and may even have a phenotype entirely different from what we already know.

Knowing the complexity of the human immune system, the limitation of this study was the in vitro controlled environment in which the endodontic filling materials were inserted, which can not represent the entire reality.

However, further studies, especially in vivo, are needed to better understand modulation of M1 and M2 phenotypes of macrophages induced by different dental materials. 


\section{Conclusion}

After data analysis, it was concluded that all the filling materials stimulated the expression TNF- $\alpha$ and IL-10, pro- and anti-inflammatory mediators, respectively. We found differences along the other proinflammatory mediators. GM-CSF was stimulated by AH Plus ${ }^{\mathrm{TM}}$, BioRoot ${ }^{\mathrm{TM}} \mathrm{RCS}$ and EndoSequence BC Sealer ${ }^{\mathrm{TM}}$. The IL-6 expression was stimulated by BioRoot ${ }^{\mathrm{TM}}$ RCS, EndoSequence BC Sealer ${ }^{\mathrm{TM}}$ and Sealapex Xpress $^{\mathrm{TM}}$. In turn, IL-1 $\beta$ was stimulated just by BioRoot ${ }^{\mathrm{TM}}$ RCS. Although, this process did not induce the macrophage polarization, resulting in a hybrid macrophage, stimulating a mixed macrophage pattern (M1/M2).

\section{ACKNOWLEDGES:}

The work was supported by FAPESP (2016/24900-9), CAPES (88881.190601/2018-01) and CNPq (140139/2019-2).

\section{Resumo}

0 objetivo deste estudo foi avaliar a modulação dos macrófagos M1 e M2 após estímulos com diferentes materiais utilizados durante o tratamento endodôntico. Em cultura de células de macrófagos derivados da medula óssea de camundongos machos $\mathrm{C} 57 \mathrm{BL} / 6$ wild-type (WT), após a exposição à cinco cimentos endodônticos: AH Plus, Sealapex Xpress, Endosequence BC Sealer, BioRoot RCS e pasta à base de hidróxido de cálcio foi realizada a análise da expressão gênica dos marcadores para macrófagos $\mathrm{M} 1$ e M2 por qRT-PCR (Cxcl10, CxCL9, iNOS, Arg1, Chil3, Retnla e MRC1) e quantificação de citocinas por Luminex ${ }^{\circledR}$ (GM -CSF, IL-10, IL-6, IL-1 $\beta$ e TNF- $\alpha$ ). Para valores normais, foi utilizado o teste ANOVA, seguido do pós-teste de Tukey. Para valores não normais, foi utilizado o teste de Kruskall-Wallis. BioRoot ${ }^{\mathrm{TM}}$ RCS e EndoSequence BC Sealer ${ }^{\mathrm{TM}}$ estimularam maior expressão de marcadores para macrófagos $M 1$, enquanto a pasta à base de hidróxido de cálcio estimulou expressão mais baixa desses marcadores gênicos. Para o marcador de proteinas para $\mathrm{M} 2$, BioRoot ${ }^{\mathrm{TM}} \mathrm{RCS}$ apresentou a maior estimulação, enquanto a pasta à base de hidróxido de cálcio também apresentou menor estimulação. Concluiu-se que os materiais obturadores avaliados aumentaram a expressão genética de marcadores pró- e anti-inflamatórios: TNF- $\alpha$ e IL-10 respectivamente. Os demais marcadores pró inflamatórios mostraram diferenças em relação aos materiais obturadores. No entanto, esse processo não induziu a polarização da resposta inflamatória, resultando em um macrófago híbrido. 


\section{References}

1. Abderrazak A, Syrovets T, Couchie D, El Hadri K, Friguet B, Simmet T, et al. NLRP3 inflammasome: from a danger signal sensor to a regulatory node of oxidative stress and inflammatory diseases. Redox Biol. 2015;4:296-307.

2. Atri C, Guerfali FZ, Laouini D. Role of Human Macrophage Polarization in Inflammation during Infectious Diseases. Int J Mol Sci. 2018;19(6):1801.

3. Chávez-Galán L, Olleros ML, Vesin D, Garcia I. Much More than M1 and M2 Macrophages, There are also CD169(+) and TCR(+) Macrophages. Front Immunol. 2015;6:263.

4. Martinez FO, Sica A, Mantovani A, Locati M. Macrophage activation and polarization. Front Biosci. 2008;13:453-461.

5. Zhuang Z, Yoshizawa-Smith S, Glowacki A, Maltos K, Pacheco C, Shehabeldin M, et al. Induction of M2 Macrophages Prevents Bone Loss in Murine Periodontitis Models. J Dent Res. 2019;98(2):200-208.

6. Ito T, Kaneko T, Yamanaka Y, Shigetani Y, Yoshiba K, Okiji T. M2 macrophages participate in the biological tissue healing reaction to mineral trioxide aggregate. J Endod. 2014;40(3):379-383.

7. Takei E, Shigetani Y, Yoshiba K, Hinata G, Yoshiba N, Okiji T. Initial transient accumulation of M2 macrophage-associated molecule-expressing cells after pulpotomy with mineral trioxide aggregate in rat molars. J Endod. 2014;40(12):1983-1988.

8. Zhu X, Yuan Z, Yan P, Li Y, Jiang H, Huang S. Effect of iRoot SP and mineral trioxide aggregate (MTA) on the viability and polarization of macrophages. Arch Oral Biol. 2017;80:27-33.

9. Yeh HW, Chiang CF, Chen PH, Su CC, Wu YC, Chou L, et al. Axl Involved in Mineral Trioxide Aggregate Induces Macrophage Polarization. J Endod. 2018;44(10):1542-1548.

10. Jeanneau C, Giraud T, Milan JL, About I. Investigating unset endodontic sealers' eugenol and hydrocortisone roles in modulating the initial steps of inflammation. Clin Oral Investig. 2020;24(2):639647.

11. Souza GL, Rosatto CMP, Silva MJB, Silva MV, Rocha Rodrigues DB, Moura CCG. Evaluation of apoptosis/necrosis and cytokine release provoked by three root canal sealers in human polymorphonuclears and monocytes. Int Endod J. 2019;52(5):629-638.

12. Bezerra da Silva RA, Nelson-Filho P, Lucisano MP, De Rossi A, de Queiroz AM, Bezerra da Silva LA. MyD88 knockout mice develop initial enlarged periapical lesions with increased numbers of neutrophils. Int Endod J. 2014;47(7):675-686.

13. Ataoğlu $T$, Ungör $M$, Serpek $B$, Haliloğlu $S$, Ataoğlu $H$, Ari H. Interleukin-1beta and tumour necrosis factor-alpha levels in periapical exudates. Int Endod J. 2002;35(2):181-185.

14. Shiratori T, Kyumoto-Nakamura Y, Kukita A, Uehara N, Zhang J, Koda K, et al. IL-1 $\beta$ Induces Pathologically Activated Osteoclasts Bearing Extremely High Levels of Resorbing Activity: A Possible Pathological Subpopulation of Osteoclasts, Accompanied by Suppressed Expression of Kindlin-3 and Talin-1. J Immunol. 2018;200(1):218-228.

15. Lio D, Scola L, Crivello A, Colonna-Romano G, Candore G, Bonafé M, et al. Inflammation, genetics, and longevity: further studies on the protective effects in men of IL-10 -1082 promoter SNP and its interaction with TNF-alpha -308 promoter SNP. J Med Genet. 2003;40(4):296-299.

16. Yuan $Z$, Zhu $X$, Li Y, Yan $P$, Jiang $H$. Influence of iRoot SP and mineral trioxide aggregate on the activation and polarization of macrophages induced by lipopolysaccharide. BMC Oral Health. 2018;18(1):56.

17. Benoit $M$, Desnues $B$, Mege JL. Macrophage polarization in bacterial infections. J Immunol. 2008;181(6):3733-3739.

18. Aarstad HH, Vintermyr OK, Ulvestad E, Kross K, Heimdal JH, Aarstad HJ. In Vitro-Stimulated IL-6 Monocyte Secretion and In Vivo Peripheral Blood T Lymphocyte Activation Uniquely Predicted 15-Year Survival in Patients with Head and Neck Squamous Cell Carcinoma. PLoS One. 2015;10(6):e0129724.

19. Gomes-Filho JE, Watanabe S, Gomes AC, Faria MD, Lodi CS, Penha Oliveira SH. Evaluation of the effects of endodontic materials on fibroblast viability and cytokine production. J Endod. 2009;35(11):1577-1579.

20. Martinho FC, Camargo SEA, Fernandes AMM, Campos MS, Prado RF, Camargo CHR, et al. Comparison of cytotoxicity, genotoxicity and immunological inflammatory biomarker activity of several endodontic sealers against immortalized human pulp cells. Int Endod J. 2018;51(1):41-57.

21. Nathan C, Ding A. Nonresolving inflammation. Cell. 2010;140(6):871-882. 
22. Huang X, LiY, Fu M, Xin HB. Polarizing Macrophages In Vitro. Methods Mol Biol. 2018;1784:119126.

23. Couper KN, Blount DG, Riley EM. IL-10: the master regulator of immunity to infection. J Immunol. 2008;180(9):5771-5777.

24. Spiller KL, Nassiri S, Witherel CE, Anfang RR, Ng J, Nakazawa KR, et al. Sequential delivery of immunomodulatory cytokines to facilitate the M1-to-M2 transition of macrophages and enhance vascularization of bone scaffolds. Biomaterials. 2015;37:194-207.

25. Witherel CE, Abebayehu D, Barker TH, Spiller KL. Macrophage and Fibroblast Interactions in Biomaterial-Mediated Fibrosis. Adv Healthc Mater. 2019;8(4):e1801451. 